\title{
AN ECOLOGICAL STUDY ON RODENTS OF NATURAL VEGETATION AND FARM LANDS IN SILTIE, CENTRAL ETHIOPIA
}

\author{
Mulatu Osie, Afework Bekele and M. Balakrishnan * \\ Faculty of Life Sciences, Addis Ababa University, PO Box 1176, Addis Ababa \\ Ethiopia. E-mail: balak212@yahoo.com
}

\begin{abstract}
An ecological study on species composition, distribution, relative abundance and habitat association of rodents was conducted in Siltie natural vegetation and nearby farmlands during July 2008 - March 2009. Five habitat types, three from natural and two from agricultural fields were randomly selected based on representation of the main vegetation zones. In each habitat type, one representative grid was selected for live trapping. In addition, rodents were also snaptrapped from these habitats. A total of 562 captures was made in 2940 live-trap nights and 87 in 1200 snap-trap nights. Species of small mammals trapped were Mastomys natalensis (33.3\%), Arvicanthis dembeensis (23.0\%), Mastomys erythroleucus (12.1\%), Stenocephalemys albipes $(8.4 \%)$, Desmomys harringtoni (6.0\%), Mus mahomet (5.9\%), Tatera robusta (5.1\%), Lophuromys flavopunctatus $(2.8 \%)$, Rattus rattus (2.5\%) and Arvicanthis niloticus $(0.9 \%)$. The trap success varied significantly from habitat to habitat. Population density of rodents was high in the bush land and forest habitats. Plant matters were the most common food items revealed from the stomach contents of snaptrapped individuals. A. dembeensis, M. Mahomet, D. harringtoni and M. natalensis were recorded as major pests in the study area. Breeding was seasonal for most of the species trapped. The number of embryos varied both within and among species.
\end{abstract}

Key words/phrases: Abundance, farmlands, natural habitats, small mammals, trap success

\section{INTRODUCTION}

Rodents constitute the most diverse group of mammals (Vaughan et al., 2000). Nearly, 40\% of all mammal species belong to this order. They account for 29 living families, 443 genera and more than 2000 species (Wilson and Reeder, 1993). The number of rodent species has been increasing from time to time as a result of the development of new techniques of identifying sibling and cryptic species (Davis, 1963). Rodents are nearly cosmopolitan in habitat utilization, morphology, behaviour and life history strategies.

The distribution and relative abundance of rodents are highly determined by the fluctuations in the availability of food and water resources. The nature and density of vegetation in the habitat affect the distribution and abundance of rodents (Afework Bekele and Leirs, 1997). The timing of reproduction in rodents is also influenced by environmental factors (Vaughan et al., 2000). Habitat selection is considered as an important factor in community dynamics of small mammals (Shanker, 2001). This is because of their high potential for reproduction and ability of their invasion. The study of diet of rodents is extremely significant for determining day to day activity, evolution, life history strategies and ecological role of rodents (Krebs, 1998). Diets of rodents are mostly studied by analyzing stomach contents or less frequently by analysing faecal materials (Workneh Gebresilassie et al., 2004).

Studies on small mammals of Ethiopia have been carried out by Yalden (1988a, b), Afework Bekele and Leirs (1997), Workneh Gebresilassie et al. (2004) and Demeke Datiko et al. (2007). However, the population dynamics of rodent communities is only poorly known for many of the regions of Ethiopia. Hence, the present investigation was undertaken to study the species composition, distribution, abundance and habitat association of the small mammal fauna at Siltie, central Ethiopia.

* Author to whom all correspondence should be addressed. 


\section{THE STUDY AREA AND METHODOLOGY}

\section{The study area}

The study area, Siltie Zone is one of the 13 administrative zones and 9 special Woredas of the Southern Nations Nationalities and Peoples Regional State of Ethiopia (Fig. 1). It is located at the western border of the Ethiopian Rift Valley, along the Addis Ababa - Arba Minch main road, $171 \mathrm{~km}$ southwest of Addis Ababa. Its location is $38^{\circ} 1^{\prime}-38^{\circ} 4^{\prime} \mathrm{E}$ longitude and $7^{\circ} 8^{\prime}-8^{\circ} 0^{\prime} \mathrm{N}$ latitude. The area is characterized by a mild sub-tropical temperature range of $10.1-28.5^{\circ} \mathrm{C}$ with three temperature zones (cold zone comprising 20.5\%, mild weather zone comprising $62.9 \%$, and dry zone comprising $16.6 \%$ of the total land area). The annual mean temperature of the area is about $21^{\circ} \mathrm{C}$. The maximum temperature is in February and the minimum in July. The annual rainfall of the area follows a bimodal regime characterized by two distinct peaks. Most of the rainfall is during June-September (long rainy season), while the short rainy season is during March-April. The driest season is from November to February and the other dry period is from May to mid-June. The vegetation type of the area is sparse woodland and bush land dominated by Acacia sp. The dominant Acacia species are A. tortilis, A. senegal and A. seyal. There are also shrubs and small plantations. Cordia africana, Juniperus procera and Brassica nigra var. acephala are endemic plants in the area.

\section{Methodology}

Based on the vegetation composition, the study area was divided into natural vegetation and farmlands. Five live-trapping grids, each of $70 \mathrm{~m}$ $\times 70 \mathrm{~m}=4900 \mathrm{~m}^{2}$, were established (three from natural vegetation and two from farmlands) (Linzey and Kesner, 1997). A total of 49 Sherman live-traps were set per grid at $10 \mathrm{~m}$ interval between points during both wet and dry seasons. Traps were baited with peanut butter and crushed pea. Traps were covered with hay and plant leaves during the dry season in order to protect the trapped animals against strong heat. Traps were checked twice a day, early in the morning (06:00-08:00 h) and late in the afternoon (17:00-18:30 h) for three consecutive days. The captured animals were marked by toe clipping and data on weight, sex, approximate age (juvenile, sub-adult, adult) based on their weight and pelage colour (Afework Bekele, 1996a) and reproductive conditions of females (closed or perforated vagina, pregnant or non-pregnant, and lactating or non-lactating) and for males the position of testes (scrotal or inguinal) were recorded. For species identification, taxonomic characteristics listed in Yalden et al. (1976) and Afework Bekele (1996a) were used. Voucher skins and skulls were prepared and compared with the specimens available in the Zoological Natural History Museum of Addis Ababa University.

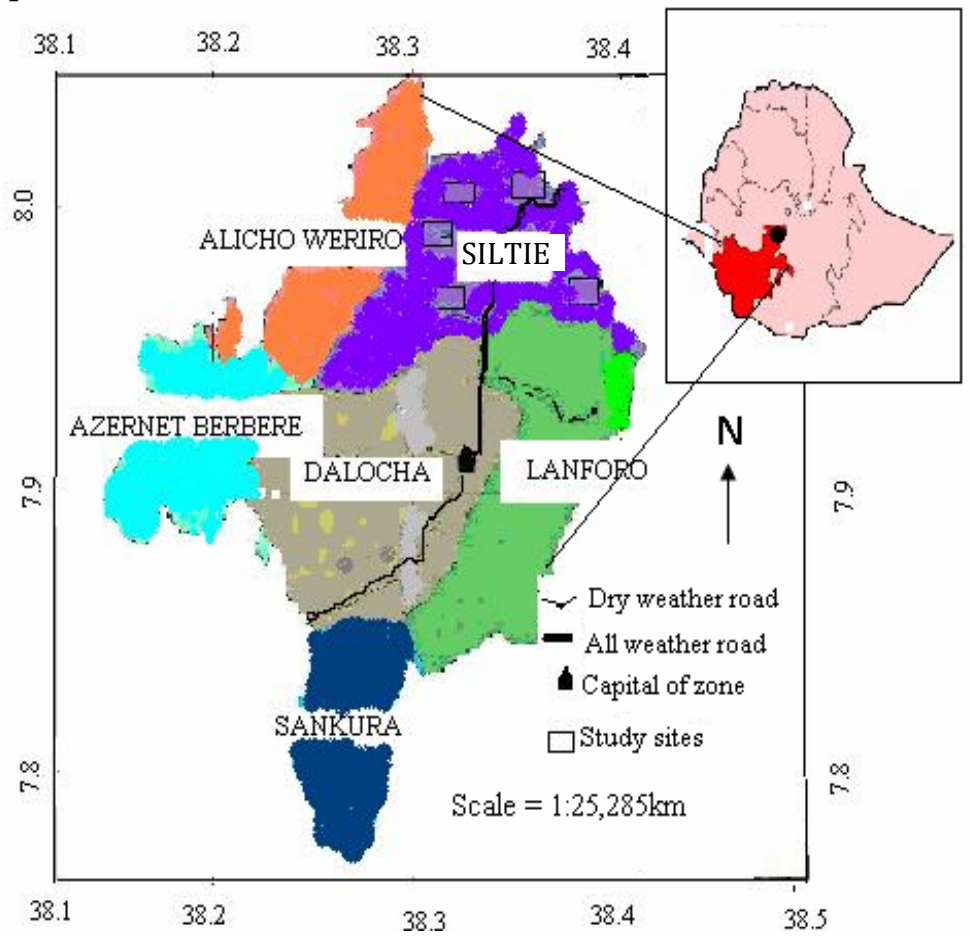

Fig. 1. Map of Siltie area showing study sites, with map of Ethiopia in inset. 
In addition to live trapping, 25 snap traps were set, 5 in each of the habitat types, during all trapping sessions. These were set at least $300 \mathrm{~m}$ away from the live trapping grids. The snap trapped rodents were used for embryo counts and stomach content analysis during both wet and dry seasons. They were dissected and the pregnant females were observed for number of embryos. The stomach contents were removed and individually preserved in $70 \%$ alcohol. Samples were spread over a glass slide and observed under a light microscope in the laboratory for identification of undigested particles. Those stomach contents which could be identified were grouped into seeds, leaves, roots, earthworms and arthropods, and listed for four species, based on the relative abundance of snap-trapped rodents.

\section{Data analyses}

SPSS version 15.0 computer program was used to analyse the data. Chi-square test and cross tabulation were used to compute species distribution, relative abundance and habitat association of various species of rodents. Population density of rodents was estimated as number per hectare in each of the habitat types. Simpson's Similarity Index was used to assess the similarity of different habitats with respect to the presence of rodent species. Rodent species diversity in different habitats was analysed using ShannonWeaver Index.

\section{RESULTS}

A total of 562 individual rodents were captured in 2940 trap nights. Ten species were captured during the four trapping sessions. The species composition of rodents and percentage of occurrence in different habitats are shown in Table 1. The species recorded and the relative abundances were: M. natalensis (33.3\%), A. dembeensis $(23.0 \%)$, M. erythroleucus $(12.1 \%)$, S. albipes $(8.4 \%), D$. harringtoni $(6.0 \%)$, M. mahomet $(5.9 \%)$, T. robusta (5.1\%), L. flavopunctatus $(2.8 \%)$, R. rattus $(2.5 \%)$ and A. niloticus (0.9\%). Distribution of the species varied among the different habitats. $M$. natalensis and $A$. dembeensis were the most widely distributed species. In terms of number, $M$. natalensis was the most dominant species followed by $A$. dembeensis. Mastomys erythroleucus, S. albipes and M. mahomet were absent in one of the habitat types, whereas $D$. harringtoni, L. flavopunctatus and T. robusta were absent in two of the habitat types. The other less distributed species, $R$. rattus was found only in farmlands. A. niloticus was less distributed as well as the least abundant species, captured only during the first session of the dry season, $80 \%$ of which was in forest habitat. Most of the rodents were trapped from bush land and forest habitats and the least from grassland area.

The rodent species richness in the study area was highest in the forest, with nine species and lowest in grassland, with only four species. There was a statistically significant difference in species richness among habitats $\left(X^{2}=1.92, d f=4, P<0.05\right)$. Simpson's Similarity Index was 0.32 among the five different habitats, with reference to species composition. Shannon-Weaver Index $\left(\mathrm{H}^{\prime}\right)$ for species diversity was 1.72 for both forest and bush land habitats, and 1.19, 1.59 and 1.77, respectively, for grassland, maize farm and wheat farm habitats.

Table 1. Habitat association of rodents in the study area.

\begin{tabular}{lrrrrr}
\hline \multirow{2}{*}{ Species } & \multicolumn{5}{c}{$\begin{array}{c}\text { Abundance in each } \\
\text { habitat type (\%) }\end{array}$} \\
\cline { 2 - 6 } & \multicolumn{1}{c}{ F } & BL & GL & MF & WF \\
\hline Mastomys natalensis & 24.6 & 55.6 & 11.8 & 6.4 & 1.6 \\
Arvicanthis dembeensis & 18.6 & 38.7 & 17.1 & 13.2 & 12.4 \\
Mastomys erythroleucus & 16.2 & 52.9 & 22.1 & -- & 8.8 \\
Stenocephalemys albipes & 29.8 & 40.4 & -- & 29.8 & 6.4 \\
Desmomys harringtoni & 17.7 & 44.1 & -- & -- & 38.2 \\
Mus mahomet & 18.2 & -- & 6.1 & 39.4 & 36.4 \\
Tatera robusta & 6.9 & 93.1 & -- & -- & -- \\
Lophuromys flavopunctatus & 6.3 & 93.7 & -- & -- & -- \\
Rattus rattus & -- & -- & -- & 64.3 & 35.7 \\
Arvicanthis niloticus & 80.0 & 20.0 & -- & -- & -- \\
Number of species & 9 & 8 & 4 & 5 & 7 \\
\hline
\end{tabular}

$\mathrm{F}=$ Forest, $\mathrm{BL}=\mathrm{Bush}$ land, $\mathrm{GL}=$ Grassland, $\mathrm{MF}=$ Maize farm, $\mathrm{WF}=$ Wheat farm,$--=$ Absence . 
The number of species captured during the wet and dry seasons was 9 and 10, respectively. The overall species richness between the two seasons was not different $\left(X^{2}=0.05, \mathrm{df}=1, \mathrm{P}>0.1\right) . A$. niloticus was captured only during the dry season. The abundance of rodents between the wet and dry seasons was $57.5 \%$ and $42.5 \%$, respectively. There was no statistically significant difference between abundance of species and seasons $\left(X^{2}=0.8, \mathrm{df}=1, \mathrm{P}>0.05\right)$. However, the population size of the rodents trapped varied significantly between seasons $\left(\chi^{2}=40.83, d f=3\right.$, $\mathrm{P}<0.01)$. The estimated population density of each of the rodent species in different habitat types is given in Table 2 . The highest density was estimated for M. natalensis and the lowest was for A. niloticus. The cumulative rodent density was high in bush land and low in wheat farm.

Table 2. Estimated population density of rodents in each of the habitat types (per ha).

\begin{tabular}{lrrrrr}
\hline \multirow{2}{*}{ Rodent species } & \multicolumn{5}{c}{ Density/ha in each habitat type } \\
\cline { 2 - 6 } & F & BL & GL & MF & WF \\
\hline$M n$ & 92 & 208 & 44 & 24 & 6 \\
Ad & 48 & 100 & 44 & 34 & 32 \\
$M e$ & 22 & 72 & 30 & -- & 12 \\
$S a$ & 28 & 38 & -- & 22 & 6 \\
$D h$ & 12 & 30 & -- & -- & 26 \\
$M m$ & 12 & -- & 4 & 26 & 24 \\
$T r$ & 4 & 54 & -- & -- & -- \\
$L f$ & 2 & 30 & -- & -- & -- \\
$R r$ & -- & -- & -- & 18 & 10 \\
An & 8 & 2 & -- & -- & -- \\
Total & 22 & 534 & 122 & 124 & 116 \\
\hline
\end{tabular}

$\mathrm{F}=$ Forest, $\mathrm{BL}=\mathrm{Bush}$ land, $\mathrm{GL}=\mathrm{Grassland}, \mathrm{MF}=$ Maize farm, $\mathrm{WF}=$ Wheat farm, $M n=M$. natalensis, $A d=A$. dembeensis, $M e=M$. erythroleucus, $S a=S$. albipes, $D h=D$. harringtoni, $M m=M$. mahomet, $T r=T$. robusta, $L f=L$. flavopunctatus, $R r=R$. rattus, $A n=A$. niloticus, $--=$ Absence.

Out of the 562 individuals of live-trapped rodents, males comprised $310(55.2 \%)$ and females $252(44.8 \%)$. There was no statistically significant difference between the abundance of males and females $\left(X^{2}=5.97, \mathrm{df}=1, \mathrm{P}>0.1\right)$. Further, there was no significant difference in the abundance of males and females between seasons (1:1.3 female:male during the wet season and 1: 1.2 during the dry season) $\left(\chi^{2}=1.4, d f=1\right.$, $P>0.05)$. The difference in sex ratio of rodents in different habitats was also statistically not significant $\left(X^{2}=0.88, d f=4, P>0.05\right)$. All age groups were represented in the population of captured rodents during both dry and wet seasons.
Juvenile, sub-adult and adult individuals constituted $38.6 \%, 26.9 \%$ and $34.5 \%$, respectively. Juvenile, sub-adult and adult rodents accounted for $22.9 \%, 30.7 \%$ and $46.4 \%$, respectively, during the wet season and $59.8 \%, 21.8 \%$ and $18.4 \%$ during the dry season.

Among the five study sites, the trap success of rodents differed from habitat to habitat and season to season. More individuals were captured from the bush land $267(47.5 \%)$ and less from the wheat farm 58 (10.3\%). The overall trap success, including recaptures was $19.1 \%$. The variation was statistically significant $\left(X^{2}=285.1\right.$, $\mathrm{df}=4, \mathrm{P}<0.001)$ among the different habitats. The trap success for the wet and dry seasons was 21.9 and 16.3, respectively. The variation between seasons was insignificant $\left(X^{2}=1.03, \mathrm{df}=1, \mathrm{P}>0.05\right)$. Maximum number of individuals was captured from bush land area during the dry season (167, $56.8 \%$ ) and least from the wheat farm during the dry season $(17,5.8 \%)$. There was a significant statistical difference $\left(X^{2}=45.63, \mathrm{df}=4, \mathrm{P}<0.1\right)$ in the trap success among habitat types during the two seasons.

Out of the total adult females captured, 84 $(33.3 \%)$ were pregnant and $72(28.6 \%)$ were lactating. Most of the females trapped during the wet season were in reproductively active state. More pregnant females were captured during the wet season than during the dry season. The total number of pregnant females trapped during different seasons was statistically significant $\left(\mathrm{X}^{2}=40.05, \mathrm{df}=1, \mathrm{P}<0.001\right)$. Among the captured males, 212 (68.4\%) were scrotal and 98 (31.6\%) were abdominal. The variation was significant $\left(X^{2}=41.92\right.$, $\mathrm{df}=1, \mathrm{P}<0.001$ ).

The number of embryos recorded from snaptrapped females varied both within and among species. The highest number recorded (10) was for M. natalensis within the range of 8-10, and the least (4) was for $D$. harringtoni and $R$. rattus within the range of $4-5$. The number of embryos in 36 captured pregnant females of five species of rodents is given in Table 3.

Undigested food fragments identified from stomach contents of four species of rodents are listed in Table 4. Plant components were the most common food recorded in all the species. Fragments of earthworms were recorded in the stomach contents of $M$. natalensis and $D$. harringtoni. 
Table 3. Number of embryos recorded from snap-trapped females.

\begin{tabular}{lcccr}
\hline Species & Season & $\begin{array}{c}\text { Adult females } \\
\text { trapped }\end{array}$ & $\begin{array}{c}\text { Pregnant females } \\
\text { trapped }\end{array}$ & $\begin{array}{c}\text { No. of } \\
\text { embryos }\end{array}$ \\
\hline A. dembeensis & Wet & 7 & 5 & $5-7$ \\
A. niloticus & Dry & 5 & 3 & $4-6$ \\
\multirow{3}{*}{ M. natalensis } & Wet & -- & -- & -- \\
\multirow{3}{*}{ D. harringtoni } & Dry & 2 & 2 & $7-8$ \\
\multirow{2}{*}{ R. rattus } & Wet & 16 & 11 & $8-9$ \\
& Dry & 12 & 8 & $8-10$ \\
& Wet & 5 & 2 & 4 \\
& Dry & 3 & 1 & 5 \\
& Wet & 4 & 2 & $5-6$ \\
\hline
\end{tabular}

-- = Absence.

Table 4. Percentage frequency of food items recorded in stomach contents of four species of snap-trapped rodents.

\begin{tabular}{lcrrrrrrrr}
\hline \multirow{2}{*}{ Species } & \multirow{2}{*}{ No. of individuals } & \multicolumn{7}{c}{ Percentage composition of food items identified } \\
\cline { 2 - 9 } & & ML & DL & MS & DS & R & EW & A & UM \\
\hline$M n$ & 7 & 20.9 & 10.4 & 8.3 & 26.3 & 12.3 & 3.7 & 8.2 & 9.9 \\
$D h$ & 3 & 15.7 & 14.2 & 25.1 & 7.6 & 21.3 & 4.3 & 7.9 & 3.8 \\
$A d$ & 5 & 14.2 & 22.1 & 14.8 & 20.6 & 9.8 & -- & 10.7 & 7.8 \\
$\operatorname{Tr}$ & 2 & 8.5 & 10.5 & 24.1 & 31.2 & 4.3 & -- & 11.3 & 9.8 \\
\hline
\end{tabular}

$\mathrm{ML}=$ Monocot leaves, $\mathrm{DL}=$ Dicot leaves, $\mathrm{MS}=$ Monocot seed, $\mathrm{DS}=$ Dicot seed, $\mathrm{R}=\mathrm{Root}, \mathrm{EW}=$ Earthworms, A=Arthropods, $\mathrm{UM}=$ Unidentified materials, $M n=M$. natalensis, $D h=D$. harringtoni, $A d=A$. dembeensis, $T r=T$. robusta,$--=$ Absence.

Seven species of rodents were recorded as pests of maize and wheat in the study area. They are $A$. dembeensis, M. mahomet, $D$. harringtoni, $M$. natalensis, S. albipes, $R$. rattus and M. erythroleucus. The most abundant pest species was $A$. dembeensis $40(27.2 \%)$, followed by M. mahomet $25(17.0 \%), D$. harringtoni $20(13.6 \%)$, and M. natalensis $19(12.9 \%)$. All trapped individuals of $R$. rattus were from farmlands.

\section{DISCUSSION}

During the present study, ten species of rodents were trapped. Among these, three species ( $T$. robusta, L. flavopunctatus and A. niloticus) were recorded only from natural habitats. On the other hand $R$. rattus, being a pest, was recorded only from farmlands. The presence of species specific habitat requirements and continuous food supply might contribute for this difference in the occurrence of rodents in different habitat types. M. natalensis was the most widely distributed and abundant among the rodent species captured. Lavrenchenko et al. (1998) showed that it was a common rodent in most parts of the West, Central and East African countries. It is also distributed widely over most of the Ethiopian regions (Afework Bekele and Leirs, 1997; Tadesse Habtamu and Afework Bekele, 2008). Due to the high breeding potential, A. dembeensis is a very common rodent in Ethiopia. Most studies have revealed the existence of this species in different parts of Ethiopia (Afework Bekele, 1996b; Afework Bekele and Leirs, 1997). During the present study, it was recorded as the second most abundant species next to $M$. natalensis. The grass loving nature and diurnal pattern of behaviour necessitate dwelling in more vegetation cover to protect itself from predators. Afework Bekele and Leirs (1997) also observed that the number of $A$. dembeensis was more in the grassland. A. niloticus is also a common rodent of Ethiopia, mostly recorded from Gambela and Lower Omo Valley by Bulatova et al. (2002). Mastomys erythroleucus was the third common and widespread rodent species in the study area. This species was also reported from Ziway, central Ethiopia (Afework Bekele and Leirs, 1997), Gambela region (Bulatova et al., 2002) and 
from Alatish National Park (Tadesse Habtamu and Afework Bekele, 2008).

Stenocephalemys albipes was commonly trapped from forest, bush land, maize farm and wheat farm. Yalden $(1988 a, b)$ reported this species to be common in the Bale Mountains National Park, Chencha and Bulto-Bonke near Arbaminch. It is one of the endemic rodent species of Ethiopia (Yalden, 1988b; Afework Bekele, 1996a and b; Bulatova et al., 2002). Desmomys harringtoni is a widespread rodent species on the Ethiopian plateau, on both sides of the Rift Valley (Yalden et al., 1976). Afework Bekele (1996b) reported the occurrence of this endemic species in the Menagesha-Suba State Forest. Agerie Addisu (2007) recorded this species from Ziway at an altitude range between 1,585 and 1,635 masl.

In the present study area, $M$. mahomet preferred crop farm to natural habitat and was not trapped from bush land. Tadesse Habtamu and Afework Bekele (2008) indicated that $M$. mahomet occurred in the lowlands of Ethiopia. Workneh Gebresilassie et al. (2004) have reported that this species is a major pest in maize farms in northern parts of Ethiopia. T. robusta has extensive geographical distribution. Dawit Kassa and Afework Bekele (2008) reported the occurrence of this species in Kenya, Sudan, the Rift Valley and Omo Valley of southern Ethiopia. Afework Bekele and Leirs (1997) also described the existence of this species in the Koka area, central Ethiopia. Yalden (1988b) indicated that this species mostly occurs in the altitudinal ranges between 200 and 1700 masl. In the present study, this species was recorded at altitudes between 1500 and 2000 masl. The present finding of this species is in a new altitudinal range. It was trapped only from forest and bush land habitats. Lophuromys flavopunctatus, the brush-furred rat, is a highly successful and ubiquitous rodent, widely distributed in bushy and forest habitats (Yalden, 1988b). In the present study area, its distribution was limited. It was recorded only from the forest and bush land habitats. This might be due to the open nature of habitats in the study area. As Nowak (1999) stated, it is common in areas with dense vegetation cover. Rattus rattus, commonly called the black rat, preferred only cereal field and trapped only from maize and wheat farms during the present investigation. Its population size in the study area was low. Agerie Addisu
(2007) recorded this species from maize farm in Ziway during the wet season.

Habitat preference and abundance of rodents varied in different habitat types of the study area. This depended upon the nature and density of the vegetation for food and shelter. As a result, more rodent species were recorded from natural habitats than farmlands. Among the five different habitat types in the study area, forest and bush land habitats were the most preferred. Species richness, abundance and habitat preference in the study area are comparable with earlier reports from Uganda (Delany, 1964), and Ethiopia (Afework Bekele, 1996b; Dawit Kassa and Afework Bekele, 2008). The preference of natural habitats by rodents is due to the heterogeneity of the habitat, which can support continuous food supply and suitable vegetation cover throughout the year. Abundance of rodents was higher in the bush land than in the forest. The vegetation cover, moisture content, food and moderate temperature of bush land might support better abundance of rodents. The species composition and abundance in the grassland habitat was low compared with other natural habitats in the study area. Grazing of domestic animals results in habitat disturbance and hence the habitat becomes less suitable for rodents. Further, the lower vegetation cover in the grasslands, especially during the dry season exposes rodents to high temperatures and to predators. Farmlands were less preferred by most rodent species of the study area, except the pest rodents. Homogenous vegetation and water logging in the farmlands are not suitable for rodents to survive. However, results of the present study have shown that the populations of pest rodents increased during fruiting period in the farms. This correlates with the availability of food in the farmlands. Workneh Gebresilassie et al. (2004) reported that the abundance of rodents in the farmland was high during the reproductive phase of the crops.

The seasonal changes in weather and vegetation types of the present study area result in changes in the distribution, species richness, diversity and abundance of small mammals. Thus, abundance of rodents was low in the early wet and late dry seasons and high in the late wet and early dry seasons. In the present study, the number of pregnant females and scrotal males increased during the wet season. This shows that 
the breeding time of most rodents was during the wet season. Different age groups were represented in the recorded population during both seasons. However, the number of adult females and juveniles were high during the wet season and less during the dry season. Even for the abundant species such as $M$. natalensis and $A$. dembeensis, adult females and young individuals were rarely trapped during the dry season. This indicates that reproduction of most rodent species was during the wet season. Sicard and Fuminer (1996) also reported that the breeding pattern of many African rodents is related to rainfall.

Trap success showed significant variation from habitat to habitat and from season to season. The mean trap success in the study area was 19.1\% with variation among habitats. Yalden (1988a) obtained $24.27 \%$ trap success from Harrena Forest, Ethiopia. Trap success is influenced by factors such as food availability and rainfall, which have direct influence on vegetation and hence in quality and quantity of food affecting the reproductive pattern and shelter of rodents (Taylor and Green, 1976).

Population density estimation of rodents varied from 116/ha in wheat farm to 534/ha in bush land area. Among the different trapping sessions, the second wet season had the highest rodent population followed by the first dry season. The population of most rodent species was less during the second dry season and during the first wet season. The observed fluctuation of population density could be attributed to variation in reproductive patterns, vegetation cover and availability of food and water. The weight of most rodents during the wet season was higher than that during the dry season. This is due to the quantity and quality of food. Similarly, the number of embryos recorded was less during the dry season. However, the number of females with embryos snap-trapped during the present investigation was insufficient to relate to the seasonality in the reproductive patterns of the distinct taxa.

Information from the stomach content analysis has shown the food preference, habitat selection, seasonal fluctuation and pest status of rodents. Even though, identification of each part of the content at species level was difficult, arthropods were identified from the contents of head, legs and wings. Regardless of the frequency, all examined rodents consumed plant matters and arthropods during both seasons. Tatera robusta preferred seeds to other parts of plants. Generally, leaves, seeds and arthropods were the main diets of rodents. Mastomys natalensis and A. dembeensis consumed more grains. Mastomys erythroleucus and $M$. mahomet are also grain eaters. They were also recorded as major pests in most parts of Africa including Ethiopia. The multimammate rat (M. natalensis) and $A$. dembeensis are the most noxious Murid pests in eastern Africa (Leirs et al., 1996). Mastomys and Arvicanthis were recognized as the major pest rodent species whereas Tatera and Mus were minor pests (Afework Bekele et al., 2003). Although the abundance of $R$. rattus was relatively less, it was recognized as pest on maize and wheat crops. The abundance and dietary results of the described rodents confirm that the borders of farmlands as well as their adjacent non-crop habitats were important for harbouring more pests than the centres. This might be due to habitat heterogeneity and availability of cover.

\section{ACKNOWLEDGEMENTS}

We are thankful to the Department of Biology, Addis Ababa University for providing financial assistance and field and laboratory facilities to carry out this research work.

\section{REFERENCES}

1. Afework Bekele (1996a). Population dynamics of the Ethiopian endemic rodents, Praomys albipes in the Menegesha State Forest. J. Zool. Lond. 238:1-12.

2. Afework Bekele (1996b). Rodents of the Menegesha State Forest, Ethiopia, with an emphasis on the endemic Praomys albipes Rüppel 1842. Trop. Zool. 9:201-212.

3. Afework Bekele and Leirs, H. (1997). Population ecology of rodents of maize fields and grassland in central Ethiopia. Belg. J. Zool. 127:39-48.

4. Afework Bekele, Leirs, H. and Verhagen, H. (2003). Composition of rodents and damage estimates on maize farms at Ziway, Ethiopia. In: Rats, Mice and People, Rodent Biology and Management, pp. 262-263, (Sigleton, G.R., Hinds, L.A., Krebs, C.J. and Spratt, D.M., eds). Australian Centre for International Agricultural Research, Canberra. 
5. Agerie Addisu (2007). Species composition, distribution, relative abundance and habitat association of rodents in Alage (Ziway). MSc Thesis. Addis Ababa University, Addis Ababa.

6. Bulatova, N., Lavrenchenko, L., Orlov, V. and Milishnikov, A. (2002). Notes on chromosomal identification of rodent species in western Ethiopia. Mammalia 66:128-132.

7. Davis, D.E. (1963). Principles of Mammalogy. Champman and Hall, London, pp. 153-178.

8. Dawit Kassa and Afework Bekele (2008). Species composition, abundance, distribution and habitat association of rodents of Wondo Genet, Ethiopia. SINET: Ethiop. J. Sci. 31:141146.

9. Delany, M.J. (1964). An ecological study of the small mammals in Queen Elizabeth Park, Uganda. Rev. Zool. Bot. Afr. 70:129-147.

10. Demeke Datiko, Afework Bekele and Gurja Belay (2007). Species composition, distribution, relative abundance and habitat association of rodents in Arba Minch forest and farmlands, Ethiopia. Afr. J. Ecol. 45:651-657.

11. Krebs, C.J. (1998). Ecological Methodology. AddisonWesley Educational Publisher, Inc., Amsterdam, pp. 217-289.

12. Lavrenchenko, L.A., Likhnova, O.P., Baskevich, M.I. and Afework Bekele (1998). Systematics and distribution of Mastomys (Muridae: Rodentia) from Ethiopia, with the description of a new species. Z. Säugetierkunde 63:37-51.

13. Leirs, H., Verhagen, R., Verhegen, W., Mwanjabe, P. and Mbise, J. (1996). Forecasting rodent outbreak in Africa: an ecological basis for Mastomys control in Tanzania. J. Appl. Ecol. 33:937-943.

14. Linzey, A.V. and Kesner, M.H. (1997). Small mammals of a woodland Savannah ecosystem in Zimbabwe. I. Density and habitat occupancy patterns. J. Zool. Lond. 243:137-152.
15. Nowak, R.M. (1999). Walker's Mammals of the World, 6 $6^{\text {th }}$ edn, Vol. II. John Hopkins University Press, Baltimore and London, pp. 643-968.

16. Shanker, K. (2001). The role of competition and habitat in structuring small mammal communities in a tropical montane ecosystem in southern India. J. Zool. Lond. 253:15-24.

17. Sicard, B. and Fuminer, F. (1996). Environmental caves and seasonal breeding patterns in Sahelian rodents. Mammalia 60:667-675.

18. Tadesse Habtamu and Afework Bekele (2008). Habitat association of insectivores and rodents of Alatish National Park, northwestern Ethiopia. Trop. Ecol. 49:1-11.

19. Taylor, K.D. and Green, G. (1976). The influence of rainfall on diet and reproduction in four African rodent species. J. Zool. Lond. 180:367389.

20. Vaughan, T.A., Ryan, J.M. and Czaplewiski, N.J. (2000). Mammalogy, $4^{\text {th }}$ edn, Saunders College Publishing, Philadelphia, pp. 256-285.

21. Wilson, D.E. and Reeder, R. (1993). Mammal Species of the World: A Taxonomic and Geographic Reference. Smithsonian Institution Press, Washington, D.C., pp. 87-193.

22. Workneh Gebresilassie, Afework Bekele, Gurja Belay and Balakrishnan, M. (2004). Microhabitat choice and diet of rodents in Maynugus irrigation field, northern Ethiopia. Afr. J. Ecol. 42:315-321.

23. Yalden, D.W., Largen, M.J. and Kock, D. (1976). Catalogue of the mammals of Ethiopia. 2. Insectivores and Rodentia. Mon. Zool. Ital. Supplemento. 8:1-118.

24. Yalden, D.W. (1988a). Small mammals in the Harena Forest, Bale Mountains National Park. SINET: Ethiop. J. Sci. 11:41-53.

25. Yalden, D.W. (1988b). Small mammals of the Bale Mountains, Ethiopia. Afr. J. Ecol. 26:282-294. 